\title{
LA ENTREVISTA DEL PAPA LEÓN Y ATILA EN LA TRADICIÓN DE LOS TEXTOS Y EN LA REPRESENTACIÓN DE RAFAEL ${ }^{*}$.
}

\author{
Francisco J. Talavera Esteso
}

\begin{abstract}
Se expone en estas páginas un ejemplo del proceso de elaboración de un episodio histórico a través del Medievo y el Humanismo. El hecho histórico es la entrevista del papa León Magno y Atila en el año 452, cuyo resultado fue que los hunos se retiran del valle del $\mathrm{Po}$, con el consiguiente alivio para Italia. El hecho pronto se interpretó como providencial y la tradición medieval lo atribuyó exclusivamente a la entrevista y a un milagro protagonizado por san Pedro y san Pablo. El proceso de transmisión del relato tuvo una expresión verdaderamente relevante en el conocido fresco de Rafael de las Estancias del Vaticano. En el trabajo se hace una revisión selectiva de los hitos más significativos en la tradición historiográfica y hagiográfica. Y dentro de ella se indica el texto concreto que ha servido de fuente a Rafael, frente a apreciaciones erróneas o generalizadoras de la crítica antigua y moderna.
\end{abstract}

Una breve nota de Paulo Jovio en su Raphaelis Urbinatis vita podría justificar que alguien con cierto grado de osadía se viera tentado a replantear la cuestión de las influencias literarias que Rafael recibe en algunos de sus cuadros de tema histórico. Jovio -quien, como se sabe, no siempre se hace merecedor del calificativo de imparcial- ofrece sobre el pintor esta nota que se nos antoja en esta ocasión bastante razonable: en el Vaticano pintó, mas con autoridad no firme todavía, dos salas al dictado del papa Julio'. Debemos tener presente que Rafael tiene apenas veinticinco años cuando se encarga de decorar las Estancias, uno de cuyos frescos -el Encuentro de León Magno y Atila- nos servirá de contraste en la revisión de algunos textos latinos medievales y humanísticos. Las palabras de Jovio han dado pie a muchas discusiones sobre el alcance y significado de esas indicaciones previas que recibiría el pintor en su trabajo de las Estancias. Una postura bastante equilibrada que permite soslayar esa intrincada cuestión es la que adopta Ludovico Pastor: sin restar mérito al genio indiscutible de Rafael, parece natural, dice este gran historiador

* Este trabajo se presentó al Congreso Internacional “Cristianismo y tradición latina”, celebrado en Málaga en los días 25-28 de Abril de 2000.

1 Pinxit in Vaticano nec adhuc stabili autoritate cubicula duo ad praescriptum Julii pontificis. Citado por PASTOR, L.: Historia de los papas en la época del Renacimiento y de la Reforma, desde la elección de Inocencio VIII hasta la muerte de Julio II. Vers. de la $4^{a}$ ed. alem. por R. Ruiz Amado. Vol VI. Alejandro VI, Pio III y Julio II (1492-1513), Barcelona,1950, pág. 478. 


\section{Francisco J. Talavera Esteso}

de los papas, que el joven pintor escuchara no sólo al papa Julio II, sino también a los sabios humanistas que le rodeaban ${ }^{2}$. Pero antes de seguir debo confesar que mi curiosidad por estas cuestiones no me la ha suscitado una súbita reorientación profesional hacia el estudio del arte, y en particular del pintor de Urbino. Antes bien, la lectura de algunos textos humanísticos me ha llevado a contemplar con más interés algunas representaciones del genial pintor que tienen por tema un determinado episodio histórico.

Así pues, no se trata de replantear con todas sus implicaciones esa cuestión de las fuentes o influencias, tema que está por encima de mis posibilidades, sino observar desde los textos uno de los frescos de las Estancias. Por otra parte, no creo que sea mucho más lo que, desde esa perspectiva, se pueda añadir sobre la fuente literaria del Castigo de Heliodoro. En efecto, leyendo el texto bíblico de II Macabeos. 3, 2-39 se tiene el relato puntual al que se ajusta la magnífica escena de Rafael.

Los historiadores y críticos del arte suelen aceptar que en este fresco y en el Encuentro de León Magno y Atila late una intención propagandística, sugerida por Julio II e interpretada magistralmente por Rafael. Mas para éste último fresco, el Encuentro, la crítica no ofrece un texto que dé cuenta de manera tan ajustada como en el caso anterior. Los historiadores modernos remiten de manera imprecisa a un relato medieval que presenta la entrevista del papa León y Atila envuelta en un ambiente milagroso. El hecho histórico, como se sabe, tuvo lugar junto al Mincio, en el año 452. Se trata de una legación, presidida por el papa, que se entrevistó con Atila, cuando éste había invadido el norte de Italia y amenazaba llevar la destrucción hasta la misma Roma. Fruto de esa entrevista fue que Atila desiste de su avance devastador, y se vuelve al Nórico, dejando a Italia libre del terror. Este cambio repentino en las intenciones de Atila en época tardía se atribuyó a la protección milagrosa que san Pedro y san Pablo habrían dispensado a la ciudad de Roma.

Además de aquella forma imprecisa o evasiva de remitir a la fuente de Rafael, ofrecida en los estudios modernos ${ }^{3}$, existen otros datos que espolean nuestra curiosidad en el mismo sentido de hacer un intento por precisar el relato que sirvió de fuente a Rafael. Son esos datos los contenidos en Le Vite de Giorgio Vasari (15111574), obra impresa en 1550 , y reeditada varias veces en años sucesivos ${ }^{4}$. Este crítico, unos años después de la muerte del pintor, subrayaba a propósito de la estética de Rafael que para éste la pintura no era sólo hacer hombres desnudos, sino que tiene ancho campo y que, entre los perfectos pintores pueden también señalarse los que saben expresar bien y con facilidad las invenciones de las historias y sus

\footnotetext{
2 Ibid.

3 Se puede ver la referencia hecha por Pastor, el gran estudioso del papado, en ibíd., pág. 501.

4 Véase un buen resumen sobre la valoración de esta obra y sobre otros temas introductorios debido a $M^{\mathrm{a}}$. T. MÉNDEZ y J. Ma . MONTIJANO en: VASARI, G.: Las vidas de los más excelentes arquitectos, pintores y escultores italianos desde Cimabue a nuestors tiempos (Antología). Estudio, selección y traducción de $\mathrm{M}^{\mathrm{a}}$. T. Méndez Baiges y J. Mª. Montijano García, Madrid ,1998, págs. 9 y ss.
} 
caprichos con buen juicio. Y que al hacer las composiciones de las historias, quien sabe no confundirlas demasiado ni empobrecerlas, sino acomodarlas con bellas invenciones y orden, se puede llamar valiente y juicioso artífice ${ }^{5}$ Y concluyendo a propósito de la Liberación de San Pedro, dice: Intentó siempre representar las historias tal y como han sido escritas y hacer de ellas cosas elegantes y excelentes ... 6 Pero más adelante, cuando ya habla del Encuentro de León Magno y Atila, parece contradecirse: Y si bien -precisa Vasari-la historia de León III (sic) no cuenta esto, fue su capricho representarla así, como sucede muchas veces con las pinturas y la poesía, en las que se divaga por adornar una obra, sin alejarse de un modo poco conveniente de la idea principal. ${ }^{7}$ A esto se añade la ubicación errónea del histórico encuentro en Roma, "a los pies del Monte Mario." Todo ello empuja a establecer algunas premisas, que amparen una indagación de fuentes literarias. La más importante de ellas es que Rafael en las escenas de sus frescos plasma historias que suelen ser fieles a los relatos escritos. Existiría una excepción en la práctica de esa metodología, según Vasari, en el Encuentro de León Magno y Atila. Pero esto se podría explicar -no sin cierto simplismo- con la observación ampliamente compartida por los críticos de que el Encuentro sería obra del taller de Rafael. ${ }^{9}$ E igualmente podría encontrar en ello su justificación aquella dudosa apreciación de Vasari cuando afirmaba que Rafael representó la llegada de Atila a Roma y su encuentro ... ${ }^{10}$ Quede, pues, así planteado mi particular status quaestionis, o mejor, los stimuli que me han suscitado estas divagaciones.

Pero como apuntaba más arriba, fue la lectura de algún relato humanístico de los hechos históricos la que me lleva en primer lugar, como distracción y curiosidad, a identificar en ese fresco de Rafael personajes y actitudes. Esta curiosidad, en definitiva, determina la revisión de más fuentes de la tradición. Y a la postre, después de leer algunos relatos sobre el episodio, se impone la valoración provisional de que estamos ante un ejemplo más del proceso y las inflexiones producidas en la tradición cristiana medieval y humanística. Obviamente es sólo una pequeña muestra referida al relato de la famosa entrevista del papa León y Atila. No será posible ahora reconstruir detalladamente esa tradición historiográfica en el Medievo y en el Renacimiento. Para llegar a un resultado satisfactorio puede ser suficiente con señalar algunos hitos de esta tradición. Mi objetivo, pues, se limita en esta

\footnotetext{
${ }^{5}$ VASARI, G.: Le vite. Texto citado por G. L. Mellini, Rafael: Las Estancias Vaticanas, Albaicín-Sadea Edts., Granada 1966, pág. 4.

6 VASARI, G., Le vite. Cito por: VASARI, G.: Las vidas ... Estudio, selecc. y trad. de Mª T. Méndez Baiges y J. Ma . Montijano García, pág. 347.

3 VASARI, G.: Las Vidas ... op. cit., pág. 349.

8 Ibidem.

9 Véase la nota correspondiente de los traductores en: VASARI, G.: Las Vida.s ... op. cit.

10 El rigor historiográfico de Vasari es discutible a veces, y se ha discutido mucho, pero pueden ser un buen resumen de esa cuestión las palabras de Schlösser que ponen como lema de su "Introducción" los citados traductores de Vasari, Méndez y Montijano: Vasari es en todo, en el buen sentido y en el malo, el auténtico patriarca y padre de la iglesia de la nueva historia del arte, Ibíd., pág. 9.
} 


\section{Francisco J. Talavera Esteso}

ocasión a ofrecer unos testimonios de esa tradición que permitan comprobar cómo pasa el relato por la Edad Media, qué forma adopta en manos de los humanistas, y dentro de ese contexto cómo lo recoge Rafael y su genio lo plasma en el fresco de las Estancias.

La Crónica de Hidacio (h. 395 - h. 470) puede ser un buen hito para iniciar este recorrido. Como se sabe, este obispo gallego de Chaves fue contemporáneo de los hechos. El texto de su Crónica - que suele ceñirse casi exclusivamente a los sucesos de Hispania acaecidos entre 409 y 469 -, cuando se ocupa de los años 451 y 452, está dedicado por entero a las invasiones de Atila y los consiguientes pillajes. Sin duda se trataba de unos acontecimientos de gran alcance, que amenazaban seriamente el status alcanzado en esos años centrales del s. V. La narración de Hidacio en este punto se hace algo más explícita que de costumbre, y señala que la presencia de Atila en Occidente había sido anunciada por numerosos terremotos y diversos fenómenos celestes ${ }^{11}$. Según cuenta Hidacio, el ataque de Atila a las regiones del norte de Italia y su retirada, que en definitiva es lo que nos interesa ahora, se habrían producido por la concurrencia providencial del hambre, la peste y los auxilios militares enviados por el emperador de Oriente ${ }^{12}$. Pero no alude para nada a una legación del papa. La justificación de ese silencio difícilmente se puede encontrar en un pautado impuesto por las ideas o prácticas historiográficas del autor ${ }^{13}$. Más aceptable me parece recurrir a la parquedad de su información en asuntos alejados de su ámbito hispano ${ }^{14}$. En definitiva, el texto de Hidacio deja planteado un relato que atribuye la retirada de Atila a una alianza de la providencia y el poder constituido, que para el cronista es el emperador de Oriente.

Un siglo después (h. 551), Jordanes, escritor de origen godo, redacta un relato mucho más amplio sobre Atila y sus correrías bélicas. Así mismo dedica un espacio realmente amplio al famoso episodio de la invasión italiana. Trata por extenso el cerco de Aquileya, el augurio de las cigüeñas que determinó el asalto final, y la destrucción de ésta y otras ciudades. A continuación introduce en el relato un elemento nuevo ${ }^{15}$, estableciendo el contraste entre la actitud de Atila, partidario de extender la devastación hasta Roma, y la de sus consejeros que le disuadían de ello, recordándole el ejemplo de Alarico que había muerto tras el saqueo de Roma (409).

\footnotetext{
11 Cf. págs. 149 y 151.

12 El texto dice así: En el segundo año del reinado del emperador Marciano los hunos que saqueaban Italia, e incluso cuando habian destruído algunas ciudades, por voluntad divina se ven afectados ya por los rigores del hambre ya por la peste como castigo del cielo. Y también son atacados por las tropas enviadas por Marciano bajo el mando de Aecio, e igualmente son abatidos en sus propios lugares de residencia por los azotes del cielo y por el ejército de Marciano. Superados de este modo, los hunos hacen la paz. con los romanos, y regresan todos a sus regiones de origen. Y después de haber retornado hasta alli muere su rey, Atila (Pág. 154).

13 Véase un resumen sobre esta cuestión en las páginas introductorias de A. TRANOY en: HYDACE, Chronique. Introd, texte critique, trad. par A. Tranoy, París, 1974, I pág. 58-62.

14 Ibid., pág. 53.

15 Jordanes reconoce que el dato lo toma del historiador Prisco (Get. XLII, 222).
} 
Cuando el rey se debatía en esas dudas, vino hasta él una agradable legación romana, acercándosele el papa León en persona. Esto último, con la indicación de que el encuentro se produjo junto a un vado del rio Mincio, es el único apunte que hace Jordanes sobre la famosa entrevista ${ }^{16}$. No deja de ser sorprendente esta parquedad, pues el narrador, sin establecer conexión alguna, continúa exponiendo lo que se puede entender que fueron los resultados de la conferencia. Añade que Atila promete la paz y emprende el retorno, no sin asegurar entre amenazas que traerá mayores desastres a Italia si no se le entrega a Honoria, hermana del emperador Valentiniano, y la dote correspondiente. Jordanes profundiza después en este episodio de Honoria ${ }^{17}$, y relata otras incursiones de los hunos que no son de interés para nuestro propósito. En cambio puede serlo subrayar ahora que el indicado vacío de su narración se puede atribuir a la labor de abreviación o compilación que realiza Jordanes con respecto a la perdida Historia Gothorum de Cassiodoro ${ }^{18}$, en donde es probable que hubiera más información sobre el acontecimiento.

Dos siglos después, la Historia Romana de Paulo Diácono recoge, para su relato de este episodio, todos los elementos vistos en la Historia de CasiodoroJordanes. Pero hay mucho más equilibrio en su narración y, por supuesto, su latín es mucho más correcto que el de Jordanes. Así la preparación de la entrevista se plantea igualmente sobre la consabida duda del rey. Pero aquí todo el proceso está personalizado en Atila que se debate entre su animosidad hacia Roma y el temor que le impone el ejemplo de Alarico. En este elemento Paulo es deudor de CasiodoroJordanes. La diferencia entre los textos es fundamentalmente la que existe entre el dominio de los recursos narrativos tradicionales exhibido por Paulo y la impericia de la redacción de Jordanes. Pero donde se aprecia claramente esa dependencia es en el pasaje de la entrevista propiamente dicha. Paulo utiliza prácticamente los mismos términos de Jordanes, pero en una redacción más fluida ${ }^{19}$. También es deudor en el relato del "affaire" de Honoria ${ }^{20}$. Sin embargo se aparta de él, introduciendo explícitamente los resultados de la entrevista, y también la referencia completa de

${ }_{16}$ Nam Leo papa per se ad eum accedens. (Get. XLII, 223).

17 A propósito del "affaire" de Honoria señala que ella, mediante un eunuco, se había ofrecido a Atila, invitándole a que la defendiera de su hermano. Jordanes toma partido contra Honoria y atribuye el ofrecimiento ut licentiam libidinis malo publico compararet. (Get. XLII, 224).

$18 \mathrm{Cf}$. BRUNHÖLZL, F.: Histoire de la littérature latine du Moyen Âge. Trad. par H. Rochais. Compl. bibliog. par J. P. Bouhot, Leiden Brepols, 1990, I, pág. 37.

${ }^{19} \mathrm{He}$ aquí los textos: Get. XLII, 223, 1-3 (ed. Giunta-Grillone): Igitur dum eius animus ancipiti negotio, inter ire et non ire, fluctuaret secumque deliberans tardaret, placita ei legatio a Roma advenit: nam Leo papa per se ad eum accedens. PAUL. DIAC. Hist. Rom. 14, 11, 13 - 14, 12, 2 (ed. Droysen): dum ergo has animo tempestates revolveret, repente illi legatio placidissima a Roma advenit. nam per se vir sanctissimus Leo papa ad eum accessit. Nótese que alguna diferencia no es atribuible a los autores sino a la variante preferida por sus editores: Get. XLII, 223, 3 accedens. Hist. Rom. 14, 12, 2 accessit.

20) No obstante en Paulo ese acontecimiento queda claramente separado de la legación del papa (la proposición de la dama, mediante el eunuco, se habría producido cuando Atila ya había abandonado Italia), y por otro lado normaliza convenientemente la situación, pues Honoria lo que solicita de Atila es que la libere de la custodia rigurosa de su hermano para el matrimonio. 


\title{
Francisco J. Talavera Esteso
}

unos hechos milagrosos que constituyen la sustancia del relato medieval. El texto se puede considerar uno de los hitos importantes de la tradición que estamos ahora siguiendo. He aquí sus palabras:

\begin{abstract}
Y el papa después que hubo entrado junto al rey bárbaro, obteniendo todo lo que deseaba, consiguió la salvación no sólo de Roma sino de Italia entera. Pues Atila había estado por voluntad divina aterrorizado, y no fue capaz de decirle al sacerdote de Cristo nada más que lo que éste previamente deseaba. Se dice así mismo que, después de la marcha del papa, Atila fue interrogado por los suyos sobre cuál era el motivo de que, en contra de su costumbre, se hubiese mostrado tan condescendiente con el papa de Roma, puesto que se había sometido prácticamente a todo lo que él le ordenaba. Entonces el rey respondió que no había sentido respeto por la persona del que se le acercó, sino que junto a él vio a otro hombre con hábitos sacerdotales, venerable por su aspecto y sus nobles canas, que le infundia terror con la espada desnuda y le amenazaba de muerte si no cumplía todo lo que aquel otro le pedía. ${ }^{2 l}$
\end{abstract}

En el relato de Paulo Diácono están ya todos los ingredientes de la versión medieval del célebre episodio milagroso. Pero no estoy insinuando que él haya sido el primero que introdujo ese elemento milagroso. En éste, como en otros episodios de ese mismo corte, Paulo recogía y daba forma historiográfica al relato de la tradición hagiográfica del Liber Pontificalis. A esa tradición es a la que apunta de modo impreciso, y quizá también con cierta desconfianza, cuando introduce la noticia del milagro bajo la fórmula "se dice". Realmente en el siglo VI (h. 530) habría quedado configurado el núcleo más antiguo y de menos rigor historiográfico de esta crónica de los papas. Después se añadieron diversas continuaciones de valor histórico desigual, hasta que en la segunda mitad del s. XV, con el espíritu del humanismo en plena vigencia, Bartholomaeus Platina emprende una nueva redacción con estilo y criterios más adaptados a los tiempos. Pero antes de llegar al humanismo es preciso mencionar, al menos, cómo se acoge el material del Liber Pontificalis en la Legenda aurea, obra escrita a mediados del s. XIII por Jacobo de Voragine. Se trata de una suma hagiográfica, ordenada según el ciclo santoral, de amplia difusión como lectura

\footnotetext{
${ }^{21}$ PAUL. DIAC.: Hist. Rom. 14, 12, 2-14: Qui (sc. Leo papa) cum ad regem barbarum introgressus esset, cuncta ut optaverat obtinens non solum Romae sed et totius Italiae salutem reportavit; territus namque nutu dei Attila fuerat nec aliud Christi sacerdoti loqui valuit nisi quod ipse praeoptabat. fertur itaque post discessum pontificis interrogatum esse Attila a suis, cur ultra solitum morem tantam reverentiam Romano papae exhibuerit, quando quidem paene ad omnia, quae ille imperasset, obtemperarit; tum regem respondisse non se eius, qui advenerat, personam reveritum esse sed alium se virum iuxta eum in habitu sacerdotali adstantem vidisse forma augustiore canitie venerabilem illumque evaginato gladio sibi terribiliter mortem minitantem, nisi cuncta, quae ille expetebat, explesset.
} 
edificante, y fuente habitual de predicadores y artistas. También se encuentra aquí nuestro episodio dentro de un relato típicamente hagiográfico. El santo -el papa S. León Magno- es el protagonista indiscutible, y está presentado como el héroe que se enfrenta al peligro bárbaro por su pueblo. El milagro es la prueba de la asistencia de Dios y garantía del éxito. También en este caso, como en Paulo Diácono, es Atila el que da testimonio de los hechos milagrosos. Pero la aparición no se produce bajo la forma de venerable sacerdote, sino como un soldado temible y amenazante.

A mediados del s. XV, pocos años antes de que apareciera la obra del citado Platina, se publicaron las Historiarum ab inclinatione Romani Imperii decades (1453) de Flavio Blondo, considerado el padre de la historiografía medieval precisamente por esta obra. Dejando aparte otras consideraciones más generales y peculiaridades evidentes, ésta de Blondo viene a ser, en la sucesión de hitos que vamos repasando, una obra que se alinea en posiciones similares a la Historia Romana de Paulo Diácono. Ambas quieren establecer diferencias con una corriente narrativa de menos exigencias formales y que servía a objetivos concretos (religioso-morales o puramente eclesiásticos). Para ello eligen el camino de la depuración estilística y el seguimiento de los criterios historiográficos de los autores antiguos. Pues bien, Flavio Blondo en el libro segundo de sus Decades también se hace eco del famoso encuentro de Atila y el papa León. Su pasaje es más extenso que el de Paulo, pero se atiene al mismo esquema. El milagro lo introduce incluso con una fórmula evasiva similar: fama est. Y las variantes afectan a la introducción de Valentiniano por primera vez en el escenario de los hechos 22 , a las notas coloristas dedicadas al "affaire" de Honoria, y a un detalle nimio, pero de cierto interés para nuestro tema. En efecto, los personajes que milagrosamente aparecen amenazantes, con sus espadas en la mano, y flanqueando al papa, aquí son dos. Seguidamente explica el historiador en un tono que se me antoja algo distante: "Y se cree que éstos fueron los apóstoles Pedro y Pablo 23 ".

22 También se podría anotar que la legación se había iniciado, según Blondo, debido a la compasión que el papa siente por su pueblo (como señalaba la Legenda aurea). Respecto a la intervención de Valentiniano, cabe subrayar que sólo en éste, entre los textos revisados hasta ahora, se le otorga al emperador de Occidente ese protagonismo en el episodio.

${ }^{23}$ He aquí el pasaje más significativo: Romani tunc et caeteri Italiae populi Athilam, qui se dei flagellum terroremque populorum diceret ac re ipsa ostenderet, horrendo pauore expectabant. Quod cum Leo pontifex Romanus, eius nominis primus, cerneret, moestus compatiensque populis, atque etiam hortante Valentiniano, legationem ad Athilam pro cunctorum salute suscepit. Repperit autem illum apud Mincium castra habentem. Ferunt nanque regem ipsum quid faceret dubium, ab ulteriori progressu a commilitonibus exercitusque sui ducibus aliquamdiu fuisse deterritum, quia illi memorarent ac in malum uerterent praesagium Halarici casum, qui parum captae urbi ac Italiae superuixit. Pendentem tamen in Italiae desolationem, ad quam eum ingenii ferocitas trahebat, facundus pontifex orando molliuit effecitque ut omissa Italia ad propria redire regna promiserit. Quae res omnem exercitum in admirationem adduxit. Sciscitantibus uero causam. respondisse Athilam fama est, non se praesulis adductum oratione id fecisse, sed magis duorum qui strictos tenentes gladios adstabant, necem sibi ac exercitui comminantes, et hi Petrus et Paulus apostoli fuisse creduntur. (BLONDI FLAVII FORLIVIENSIS Historiarum ab inclinatione Romanorum libri XXXI, Basileae, Froben, MDLIX. Lib. II, pp. 24-25). 


\section{Francisco J. Talavera Esteso}

El libro de Bartholomaeus Platina (1421-1481), al que por fin paso a referirme, se titula Liber de vita Christi ac de vitis summorum pontificum omnium, y fue publicado en 1479. Con Platina volvemos otra vez a la vieja tradición del Liber Pontificalis, pero remozada en su forma y en sus criterios narrativos con los nuevos aires del humanismo. En los folios XXVI v y XVII $r$ de la edición de 1504 recoge la biografía del papa León Magno. Y la inicia precisamente relatando el famoso episodio de su encuentro con Atila junto al Mincio. En este pasaje están presentes todos los elementos vistos en los diferentes testimonios de la tradición. He aquí sus párrafos esenciales:

Estando ya por fin Atila para ir a Roma con sus enseñas enemigas, encontrándose en la desembocadura del Mincio en el Po con el propósito de cruzar el río, se le presenta el santísimo papa León, compadecido de las calamidades que afligían a Italia y a la ciudad de Roma, y también atendiendo los ruegos de Valentiniano. El pontífice logra convencerlo de que no avance más con el ejemplo de Alarico, quien murió por decisión divina inmediatamente después de tomar la ciudad. Y si Atila se doblegó a las advertencias del buen pontífice es porque en el curso de su entrevista le pareció ver sobre su cabeza a dos hombres que empuñaban sus espadas y le amenazaban de muerte si no era obediente. Se considera que éstos eran los apóstoles Pedro y Pablo. Atila moviendo luego sus campamentos regresa a Panonia, en donde ciertamente no mucho después muere a consecuencia de una copiosa hemorragia de nariz motivada por una borrachera. Por su parte León se vuelve a la ciudad y se entrega por entero a la confirmación de la fe católica ${ }^{24}$

Interesa subrayar la forma simplificada en que el narrador presenta la escena del encuentro, fijándose en los dos protagonistas: el papa que mediante el ejemplo de Alarico persuade al rey bárbaro de que no avance más; y Atila que obedece el aviso-recomendación del pontífice, al ver sobre su cabeza a dos hombres en actitud amenazadora. Incluye también la célebre apostilla de la interpretación milagrosa.

\footnotetext{
${ }^{24}$ LEO I: ... (Attila) Iturus deinde Romam infestis signis, cum eo loci consedisset, ubi Mintius Padum influit, amnem traiecturus, uir sanctissimus Leo pontifex calamitatem Italiae et urbis Romae miseratus, adhortante etiam Valentiniano ei fit obuiam/ persuadetque Alarici exemplo, qui statim dei iudicio post captam urbem mortuus est, ne ultra progrediatur. Monitis pontificis optimi obtemperans Attila, quod dum simul loquerentur. cernere duos uiros supra caput suum strictos [structos] tenentes gladios ac mortem minitantes, nisi pareret, uisus est. Ii Petrus et Paulus apostoli putati sunt. Inde mouens Pannonias repetit, ubi non ita multo post effundente se ubertim propter ebrietatem e naribus sanguine moritur: Leo uero ad urbem rediens, totus ad confirmandam catholicam fidem conuertitur. (PLATINA, B., Hystoria de vitis periucunda diligenter recognita ..., Venetiis, a Philippo Pincio, 1504. Fol. XXVI v.- XXVII r).
} 
Pero sobre todo interesa destacar ahora que en ese texto se encuentra la fuente de la descripción pictórica que Rafael (y su escuela) desarrolla en el famoso Encuentro de León Magno y Atila. Este fresco de las Estancias presenta en un lado al papa y su comitiva, y a otro un grupo de personajes agitados en torno al rey Atila ${ }^{25}$. Éste aparece volviéndose ya y con la mirada todavía fija en el portento que ve en el cielo. En primer término un lacayo señala hacia el papa, que expone su discurso, y los restos de la Roma antigua que figuran detrás de la comitiva pontificia. También en este segundo plano, tras el grupo de los hunos, aparece una escena de fuego y destrucción. Todo este segundo escenario suele ser atribuido por los críticos a la escuela de Rafael, por encontrar en su desarrollo deficiencias incompatibles con el pincel del maestro. En definitiva, lo que se destaca en el primer plano es la figura de Atila volviéndose, según le pide el papa (obtemperans), y al mismo tiempo con los ojos puestos en los amenazantes "signos del cielo" (cernere visus est). La estrecha sintonía entre pintura y texto parece evidente, en contra de aquella apreciación del viejo Vasari, cuando a propósito de este fresco, afirmaba: y si bien la historia de León III (sic) no cuenta eso, fue su capricho representarla así. E igualmente esa tradición de textos, cristalizada en Platina, nos permite reconocer el episodio histórico del fresco, y saber realmente a lo que puede referirse un importante crítico cuando lo define como la "carga de los hunos", y explica la escena de este modo: el ejército bárbaro embiste contra el papa, pero la arremetida se deshace contra su pétrea solidez y simultaneamente es dispersado por un contraataque celestial, una especie de ofensiva aérea de S. Pedro y S. Pablo ${ }^{26}$. Esta licencia interpretativa del profesor de Harvard difícilmente podría justificar cualquier propuesta de un profano en la materia. Por eso, bordeando lo que a todas luces parece una osadía, formularé sólo una pregunta que nace de una auténtica duda. Y es que apurando aquella sintonía con el texto, ¿el espacio del segundo plano no estaría reservado al exemplum de Alarico, tan presente en la tradición, y que, según la versión de Platina, le sirvió al papa de argumento fundamental para convencer a su interlocutor? Obviamente en este supuesto las figuraciones que están en segundo plano no se deben interpretar como el ambiente geográfico real de la entrevista, sino como el recuerdo de los hechos históricos del 409, presentes en aquella entrevista. En todo caso -y sin recurrir al exemplum de Alarico- se puede entender lo que es obvio: que Atila arrastra tras de sí el fuego y la destrucción, y el papa representa a la Roma eterna. Pero la machacona repetición de los textos no permite en modo alguno traer la famosa entrevista a las puertas de Roma, aunque nos amparemos, como insinuaba Vasari, en la licencia que Horacio otorgaba a pintores y poetas ${ }^{27}$.

25 En realidad no se podría hablar - como hace un gran crítico moderno - de que "el ejército bárbaro embiste contra el papa", o de "la carga de los hunos" (cf. FREEDBERG, D.: Pintura en Italia: 1500 a 1600, Madrid, Cátedra, 1978, págs. 60 y 62).

26 Ibíd.
27 HOR. A. P., 9-10: pictoribus atque poetis quidlibet audendi semper fuit aequa potestas ("Los pintores y poetas siempre gozaron de igual libertad de atreverse a lo que fuere"). Ciertamente esa localización es todavía habitual entre algunos críticos modernos. Incluso a este fresco se le denomina "Detención de Atila 
Para reponerme de una inquietante sensación de haberme introducido en un pantanal lleno de peligros, volveré a un terreno más seguro, y atenderé a una cuestión obligada en estos casos. ¿Pudo ser accesible a Rafael y su círculo el texto de Platina? La respuesta afirmativa se apoya en dos hechos a los que me referiré brevemente. En términos generales se puede decir que la obra de Platina dejó prácticamente en desuso el viejo Liber Pontificalis. Desde su aparición en 1479 se multiplican las ediciones de su texto. Hasta el año 1600 he podido recontar, sin ánimo de ser exhaustivo, no menos de 30 ediciones. Igualmente hablan de su aceptación y demanda las continuaciones que se hicieron sobre el texto de Platina. La más famosa es la que realizó en 1505 el humanista Rafael Maffei o Volaterrano, añadiendo la vida de cuatro papas, hasta Pío III $(\dagger 1503)^{28}$. También puede ayudar a determinar la influencia de esta obra en el círculo de Rafael la comprobación de que entre los años 1504 y 1512 se hicieron seis ediciones del Platina. Coinciden estos años con el pontificado de Julio II (1503 - 1513), y también con la época en que Rafael trabaja para este pontífice en la Estancias.

En segundo término se trata de precisar con algunos datos el medio en que se pudo fraguar el diseño del fresco del Encuentro. Hay que remontarse al pontificado de Sixto IV (1471-1484), tío y protector de Julio II. Platina pertenece al círculo de humanistas de la corte papal. En ese mismo ambiente se desenvuelve otro humanista, Andrea Bussi (1417-1475), secretario de Sixto IV, bibliotecario del Vaticano, colaborador de impresores, y editor de autores clásicos y cristianos antiguos. Entre los textos editados o comentados por él están precisamente los escritos de León Mag$n^{29}$. Se comprende bien que con Julio II se produjera un ambiente favorable para las reediciones del Platina. Así mismo queda fuera de dudas que fue este papa - adalid en la lucha contra los nuevos bárbaros invasores - el que sugiere a Rafael la historia de León Magno, como figura histórica que encarna mejor que nadie al papado salvador de Roma e Italia frente al bárbaro agresor. Las connotaciones propagandísticas son evidentes en los años en que la invasión de las tropas francesas es una amenaza para Italia y el papado. Julio II no llegaría a ver la expulsión definitiva de los franceses en el verano de 1513. Estos frutos los recogió León X, quien confirmó a Rafael en sus trabajos y aumentó incluso sus responsabilidades, lo que determinaría la intervención creciente de sus alumnos en los frescos de las Estancias. Era, pues, casi obligado que la figura de este papa, sobre su famoso caballo blanco, quedase in-

a las puertas de Roma", y explícitamente se dice que está "ambientado en un realístico fondo romano con la vista del Coliseo, de los acueductos y de las ruinas de las villas diseminadas por la campiña romana" (BECATTI, G.: "Rafael y lo antiguo", en Rafael, la obra. las fuentes, la crítica...., Barcelona, 1970, vol II, pág. 534). Tal vez esas ruinas de villas corresponderían al "Monte Mario" señalado por Vasari (cf. supra).

${ }_{28}$ La edición de 1504 ya iba ampliada con la vida de Sixto IV (†1484). Así mismo en la edición de 1529 se incluyen las vidas de los papas muertos antes de ese año. E igualmente ocurre con la edición de 1540.

${ }^{29}$ Cf. MAILLARD, J. F., KECSKEMÉTI, J. y PORTALIER, M.: L'Europe des humanistes (XIV-XVII siècles), Paris, 1995, págs. 89-90. 
mortalizada en el fresco, subrayando el cruce de connotaciones propagandísticas de esta historia. Sin duda el ambiente respecto a nuestra pequeña historia no había cambiado entre la "troupe" de cortesanos ilustrados y aduladores. Dos síntomas nada más: el protonotario del papa León X, Giraldus, con motivo de la victoria sobre los franceses (verano de 1513) escribe su Hymnus ad divum Leonem Pontificem Maximum, en el que el ejemplo de León Magno vuelve a estar subrayado ${ }^{30}$. Así mismo el maestro de ceremonias de este papa, Paris de Grassis, quien figura en el fresco de Rafael en la comitiva pontificia, puso de manifiesto que la política pontificia identificaba en los bárbaros de Atila a los franceses invasores. A éstos los calificará con términos significativos y muy duros, llamándolos entre otras cosas nefandísimos rapiñadores y corruptores de lo divino y lo humano ${ }^{31}$.

No he tenido ciertamente, al redactar estas páginas, la intención de practicar el intrusismo en materias que cultivan con gran éxito admirados colegas de Historia del Arte. El extenso territorio de la tradición latina, por su carácter básico, tiene muchos aspectos fronterizos con otras disciplinas en los que mutuamente se enriquecen. En uno de esos campos he entrado con espíritu de colaboración. Y he tratado de señalar un pequeño ejemplo de esa gran tradición clásica y cristiana, que es recogida y adaptada por el Medievo; y que toma nuevos impulsos y a veces formas espléndidas en el Humanismo. Su consideración y estudio sigue siendo útil. Y sin duda no es patrimonio de unos pocos, sino de todos los interesados en asimilar y estudiar la cultura europea. En todo caso -y por lo que hace a esta pequeña incursión mía- me basta con los textos, y con haber tenido la ocasión de recordar aquí los que considero básicos en la tradición cristiana medieval y humanística de este episodio, y señalar el pasaje concreto que, a mi juicio, ha servido de fuente a la representación pictórica rafaeliana.

\footnotetext{
${ }^{30}$ Citado en PASTOR, L.: op. cit., vol. VI, pág. 502. No me ha sido posible localizar el texto en el lugar al que remite: ROSCOE, Life of Leo the Tenth, Liverpool, 1805, III, 606-609.

31 Ecclesiasticae libertatis occupatores et ecclesiarum profanatores ac omnis humanitatis et divinitatis nefandissimos raptores et corruptores. Citado por PASTOR, L.: op. cit., vol. VI, pág. 498.
} 


\section{Francisco J. Talavera Esteso}

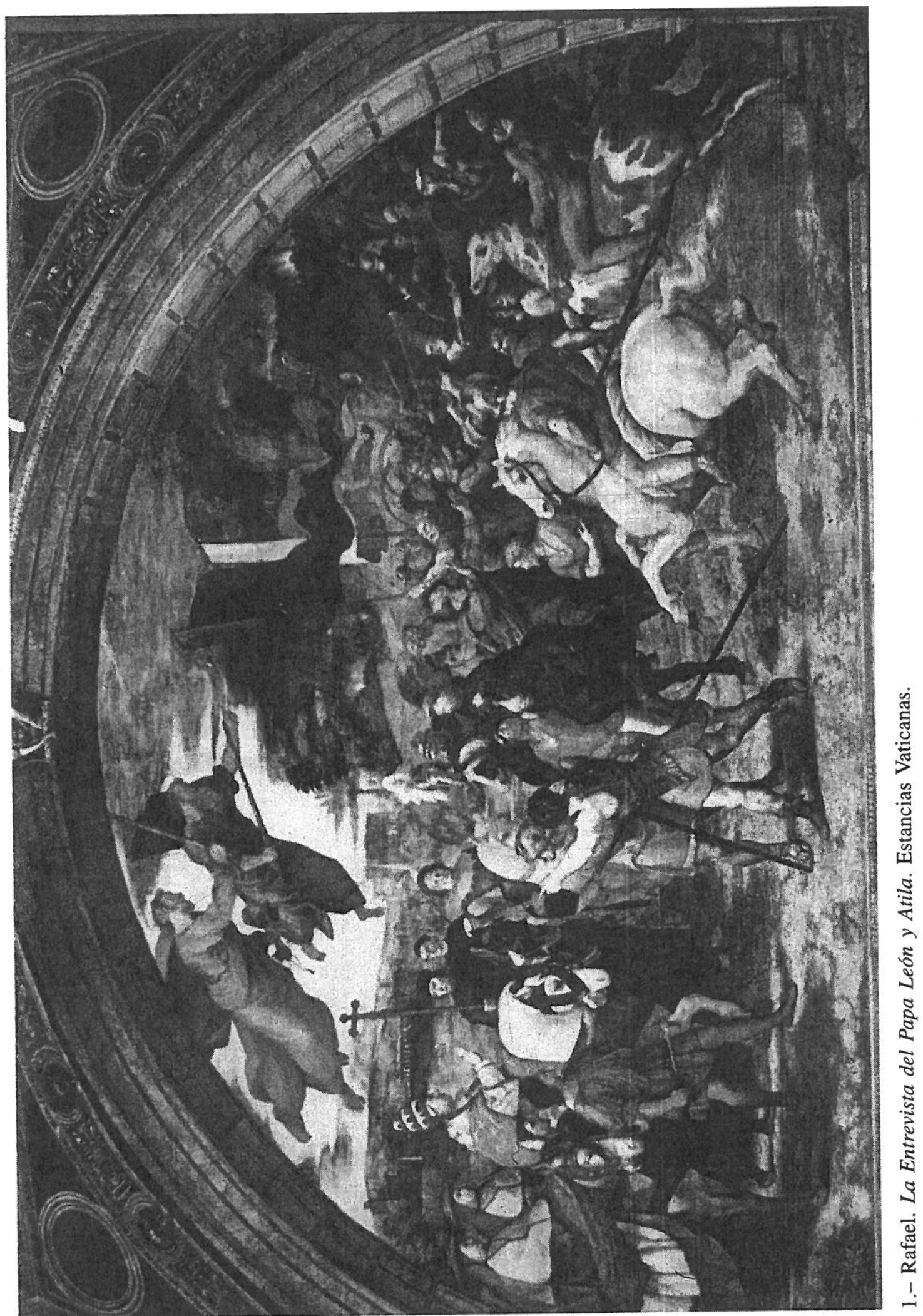

